\title{
Cervical interfacet spacers and maintenance of cervical lordosis
}

\author{
Lee A. Tan, MD, David C. Straus, MD, and Vincent C. Traynelis, MD \\ Department of Neurosurgery, Rush University Medical Center, Chicago, Illinois
}

OBJECT The cervical interfacet spacer $(\mathrm{CIS})$ is a relatively new technology that can increase foraminal height and area by facet distraction. These offer the potential to provide indirect neuroforaminal decompression while simultaneously enhancing fusion potential due to the relatively large osteoconductive surface area and compressive forces exerted on the grafts. These potential benefits, along with the relative ease of implantation during posterior cervical fusion procedures, make the $\mathrm{CIS}$ an attractive adjuvant in the management of cervical pathology. One concern with the use of interfacet spacers is the theoretical risk of inducing iatrogenic kyphosis. This work tests the hypothesis that interfacet spacers are associated with loss of cervical lordosis.

METHODS Records from patients undergoing posterior cervical fusion at Rush University Medical Center between March 2011 and December 2012 were reviewed. The FacetLift CISs were used in all patients. Preoperative and postoperative radiographic data were reviewed and the Ishihara indices and cervical lordotic angles were measured and recorded. Statistical analyses were performed using STATA software.

RESULTS A total of 64 patients were identified in whom 154 cervical levels were implanted with machined allograft interfacet spacers. Of these, 15 patients underwent anterior-posterior fusions, 4 underwent anterior-posterior-anterior fusions, and the remaining 45 patients underwent posterior-only fusions. In the 45 patients with posterior-only fusions, a total of 110 levels were treated with spacers. There were 14 patients $(31 \%)$ with a single level treated, 16 patients $(36 \%)$ with two levels treated, 5 patients $(11 \%)$ with three levels treated, 5 patients $(11 \%)$ with four levels treated, 1 patient $(2 \%)$ with five levels treated, and 4 patients $(9 \%)$ with six levels treated. Complete radiographic data were available in 38 of 45 patients ( $84 \%)$. On average, radiographic follow-up was obtained at 256.9 days (range $48-524$ days). There was no significant difference in the Ishihara index ( 5.76 preoperatively and 6.17 postoperatively, $p=0.8037$ ). The analysis had $80 \%$ power to detect a change of 4.25 in the Ishihara index at $p=0.05$. There was no significant difference in the preand postoperative cervical lordotic angles $\left(35.6^{\circ}\right.$ preoperatively and $33.6^{\circ}$ postoperatively, $p=0.2678$ ). The analysis had $80 \%$ power to detect a $7^{\circ}$ change in the cervical lordotic angle at $p=0.05$. The ANOVA of the Ishihara index and cervical lordotic angle did not show a statistically significant difference in degree of change in cervical lordosis among patients with a different number of levels of CIS insertion ( $p=0.25$ and $p=0.96$, respectively).

CONCLUSIONS In the authors' experience of placing CISs in more than 100 levels, they found no evidence of significant loss of cervical lordosis. The long-term impacts of these implants on fusion rates and clinical outcomes (particularly radiculopathy and postoperative C-5 palsies) remain active areas of interest and fertile ground for further studies.

http://thejns.org/doi/abs/10.3171/2014.10.SPINE14192

KEY WORDS cervical interfacet spacer; cervical lordosis; iatrogenic kyphosis; foraminal area

$\mathrm{C}$ ERVICAL interfacet spacers (CISs) represent a relatively new technology that can increase foraminal height and foraminal area by distraction of facet joints. ${ }^{3}$ In addition to indirect neuroforaminal decompression, these implants may be conducive to rapid fusion due to the relatively large osteoconductive surface area pro- vided and the fact that they are under compression. The implantation of the CIS is quick and technically straightforward. Goel and Shah reported their experience using titanium CISs as a stand-alone method for treatment of cervical spondylotic radiculopathy and myelopathy in 36 patients with favorable clinical outcome. ${ }^{3}$ The senior

\section{ABBREVIATION CIS = cervical interfacet spacer.}

SUBMITTED February 24, 2014. ACCEPTED October 8, 2014.

INCLUDE WHEN CITING Published online February 13, 2015; DOI: 10.3171/2014.10.SPINE14192.

DISCLOSURE Dr. Traynelis is a consultant for and a patent holder with Medtronic. He receives institutional fellowship support from Globus. 
author (V.C.T.) routinely incorporates machined allograft CISs as an adjuvant to posterior cervical fusion procedures, given the aforementioned potential benefits.

One hypothetical concern with using CISs, however, is the possibility of inducing iatrogenic kyphosis, because insertion of the spacers longitudinally distracts the cervical facet joints. Intuitively, there is concern that such distraction produces increased cervical spinal flexion, which can promote loss of lordosis or even kyphosis-especially when multiple levels are treated. The literature addressing this topic is limited to a single publication. In Goel and Shah's series of 36 patients, mild loss of lordosis was noted following surgery; however, all of their postoperative patients were found to have cervical lordosis within the normal range and none developed kyphosis. ${ }^{3}$ To our knowledge, there are no other published data addressing the effect of CIS on sagittal alignment. This retrospective case review was performed to test the hypothesis that CISs are associated with significant loss of cervical lordosis.

\section{Methods \\ Medical Records}

A retrospective review of prospectively collected data was performed. The records of patients who underwent posterior cervical fusion performed by the senior author at Rush University Medical Center between March 2011 and December 2012 were reviewed. Cervical interfacet spacers (FacetLift) were used in all patients. Ishihara indices and cervical lordotic angles were measured from pre- and postoperative standing cervical spine radiographs. Statistical analyses were performed using STATA software.

\section{Surgical Technique}

All procedures were performed after administration of general endotracheal anesthesia without intraoperative monitoring, with the head secured with a Mayfield clamp and the patient positioned prone. The dorsal cervical spine was exposed via a midline incision and subperiosteal dissection. Great care was taken to avoid detachment of the muscle insertions onto the $\mathrm{C}-2$ spinous process. Interfacet grafting was always performed as the next step. The $\mathrm{C} 4-5$ level was always treated first to maximize the facet distraction and subsequent indirect foraminal enlargement. At each facet joint the cartilage was removed using customized rasps (FacetLift) as shown in Fig. 1. The rasps all

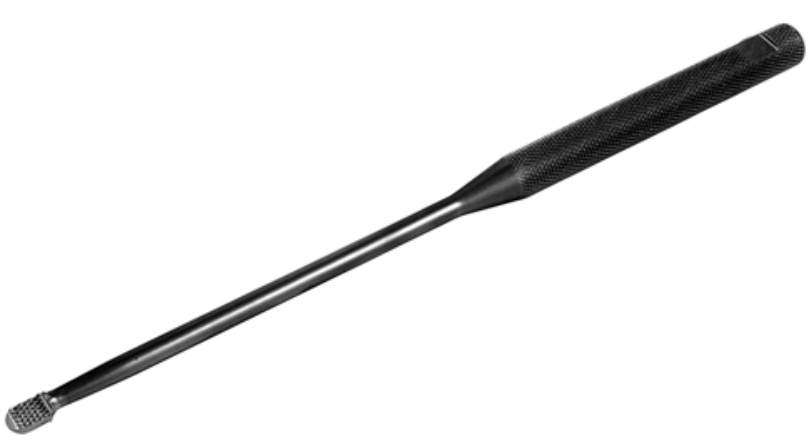

FIG. 1. Rasp used to remove cartilage in the facet joints. have an $8 \times 8-\mathrm{mm}$ width and depth, and vary in height $(2$, 3 , or $4 \mathrm{~mm}$ ). A 2-mm rasp was initially used in all cases. The rasps were increased in size until a very tight fit was achieved. Each rasp was used twice prior to attempting the next size. After rasping each facet articulation, an interfacet spacer was tamped into place (Video 1).

VIDEO 1. Clip showing machined interfacet allograft spacer insertion in the cervical spine. Copyright Vincent Traynelis. Published with permission. Click here to view with Media Player. Click here to view with Quicktime.

Multilevel cases were done with similar CIS insertion techniques at each level, as demonstrated in the video. The remainder of the surgical plan was completed. Lateral mass fixation was used in all cases. Prior to final fixation, the Mayfield device was released and manual force was applied to improve lordosis.

\section{Results}

A total of 64 patients were identified in whom 154 cervical levels were implanted with CIS. Of these, 15 patients underwent anterior-posterior fusions, 4 underwent anterior-posterior-anterior fusions, and the remaining 45 patients underwent posterior-only cervical fusion procedures. The 45 patients with posterior-only procedures had an average age of 59.5 years (range 19-82 years), including 22 female and 23 male patients, with a total of 110 levels treated with CIS. Fourteen patients $(31 \%)$ had a single level treated, 16 patients $(36 \%)$ had two levels treated, 5 patients $(11 \%)$ had three levels treated, 5 patients $(11 \%)$ had four levels treated, 1 patient $(2 \%)$ had five levels treated, and 4 patients (9\%) had six levels treated (Fig. 2). Complete radiographic data were available for $38(84 \%)$ of these 45 patients. On average, radiographic follow-up was obtained at 256.9 days (range $48-524$ days). The indications for performing multilevel posterior cervical decompression and fusion included symptomatic multilevel stenosis with preserved cervical lordosis and central cord syndrome secondary to trauma.

There was no statistically significant difference in the pre- and postoperative Ishihara index (5.76 preoperatively and 6.17 postoperatively, $\mathrm{p}=0.8037$ ) or the cervical lordotic angles $\left(35.6^{\circ}\right.$ preoperatively and $33.6^{\circ}$ postoperatively, $\mathrm{p}=0.2678$ ) in this cohort of 45 patients. Our analysis had $80 \%$ power to detect a change of 4.25 in the Ishihara index at $\mathrm{p}=0.05$, and $80 \%$ power to detect a $7^{\circ}$ change in

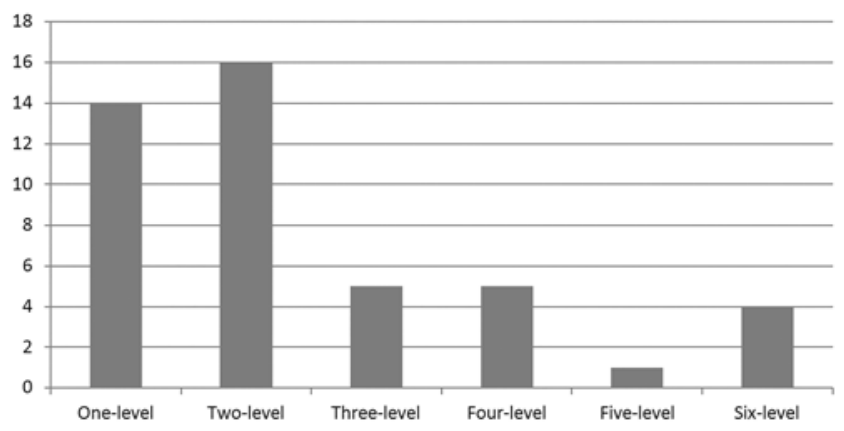

FIG. 2. Bar graph showing levels treated in posterior cervical fusions performed in 45 patients. Values on the y axis represent the number of patients. 
the cervical lordotic angle at $\mathrm{p}=0.05$. Results are shown in Fig. 3. The ANOVA of the Ishihara index and cervical lordotic angle did not show statistically significant difference in degree of change in cervical lordosis among patients with a different number of levels of CIS insertion ( $p$ $=0.25$ and $p=0.96$, respectively). Results of the ANOVA are summarized in Table 1.

\section{Discussion}

The CISs used in this series were machined allografts that were easily inserted into prepared facet joints. There are several potential benefits associated with the use of these implants. The relatively large osteoconductive surface area $(8 \times 8 \mathrm{~mm})$ coupled with the naturally applied compressive forces theoretically enhance the rate with which fusion progresses as well as the final outcome. Facet distraction stiffens the spinal segment, which may also be favorable to bony fusion. An additional benefit is the indirect neuroforaminal decompression that accompanies facet distraction. ${ }^{3}$ A recent study had demonstrated a significant increase in cervical foraminal height and area after interfacet spacer insertion. ${ }^{16}$

The presence of foraminal stenosis may be a significant risk factor for iatrogenic foraminal stenosis, which can cause complications such as postoperative C-5 palsy. $1,7,8,11$ The indirect neuroforaminal decompression afforded by the CIS can potentially reduce the risk of such complications. These potential benefits along with the relative ease of implantation make the CIS an attractive adjunct during posterior cervical fusion procedures. However, one potential drawback with using the CIS is the risk of inducing iatrogenic kyphosis and cervical malalignment.

The natural alignment of the cervical spine is lordotic. Cervical lordosis develops as an infant learns to support the weight of the head, ${ }^{5}$ and it increases with maturity. ${ }^{4}$ Hardacker et al. evaluated 100 asymptomatic volunteers and found the average cervical lordosis to be $39.4^{\circ}$ with a standard deviation of $9.5^{\circ}, 6$ however, there is not yet a universally accepted definition for a "normal" cervical lordosis. The C1-2 segment accounts for the majority of cervical lordosis, and the subaxial cervical segments provide an important but lesser amount. ${ }^{6,13}$ In a normally aligned spine in the upright neutral position, a significant portion of axial load is distributed to the posterior column. ${ }^{10,12}$ Axial load

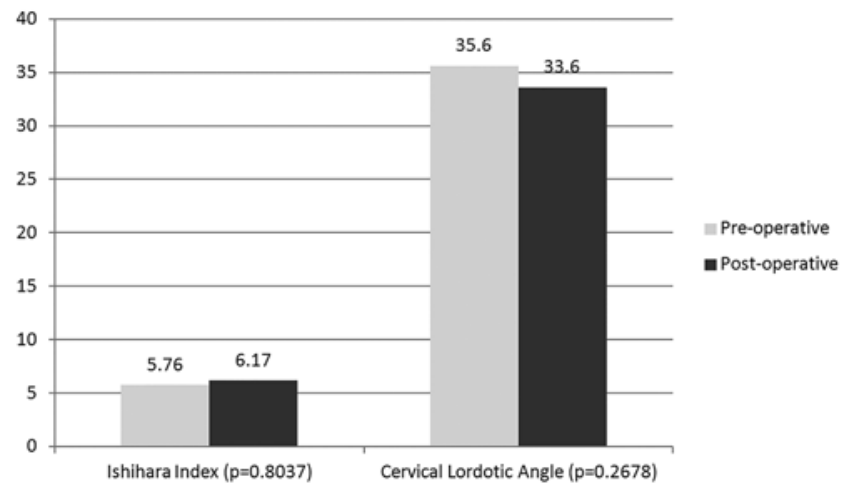

FIG. 3. Bar graph showing pre- and postoperative comparison of the Ishihara index and cervical lordotic angle.
TABLE 1. Results of the ANOVA of change in lordosis among patient groups with a different number of levels of CIS insertion

\begin{tabular}{lll}
\hline \multicolumn{1}{c}{ Change in Cervical Lordosis* } & $p$ Value & \multicolumn{1}{c}{$\mathrm{R}^{2}$} \\
\hline ANOVA Ishihara index vs no. of levels & 0.246 & 0.1809 \\
\hline ANOVA cervical lordotic angle vs no. of levels & 0.9627 & 0.0294 \\
\hline
\end{tabular}

* Calculated using postoperative measurement minus preoperative measurement.

is shifted anteriorly as lordosis is lost, and the magnitude of load transfer increases as sagittal alignment becomes more perturbed. The amplified compressive forces can potentially accelerate the degenerative process and even promote additional cervical kyphosis. ${ }^{13}$ Kyphosis leads to lengthening of the spinal cord, and over time the increased tension on the spinal cord may lead to impaired microcirculation, cord ischemia, and subsequent myelopathy. ${ }^{5,13,14}$ The increased demand on neck musculature with cervical malalignment probably also produces pain and disability. Tang et al. have demonstrated the correlation between cervical malalignment and unfavorable health-related quality of life (HRQOL) scores. ${ }^{17}$ Thus, for many reasons, normal cervical lordosis and alignment should be one of the goals during cervical spine procedures.

The Ishihara index ${ }^{2,9,18}$ and cervical lordotic angle are widely used to quantify cervical alignment. ${ }^{15}$ The Ishihara index is a validated method of cervical curvature measurement. It is a nondimensional index that correlates with the area surrounded by the $\mathrm{C} 2-7$ posterior vertebral line and the line connecting the posterior-inferior edges of C-2 and C-7. To calculate the Ishihara index, a vertical line connecting the posterior-inferior edges of C-2 and C-7 is first drawn, and then 4 additional horizontal lines-starting from the posterior-inferior edges of the C-3, C-4, C-5, and $\mathrm{C}-6$ vertebrae, respectively - are drawn perpendicular to the line connecting C-2 and C-7. The Ishihara index is the ratio of the total length of 4 horizontal segments divided by the length of the vertical line connecting $\mathrm{C}-2$ to C-7. A higher number in the Ishihara index correlates with increased lordosis, whereas a lower number correlates with decreased lordosis (Ishihara index $=0$ if the spine is perfectly straight). Cervical lordotic angle is a separate measurement reported in the literature that measures the Cobb angle between C-1 and C-7 (i.e., the angle from the line between anterior to posterior tubercles of $\mathrm{C}-1$ and the line across the inferior endplate of C-7).

The global cervical curvature was evaluated with these 2 methods. The lack of a statistically significant difference in the pre- and postoperative values of these parameters does not support the hypothesis that CISs are associated with significant loss of cervical lordosis. The results of this study demonstrate that interfacet spacer insertion in the cervical spine, even up to six levels, does not significantly impact global cervical alignment. All of our patients had final postoperative cervical lordosis that fell into the "normal" range as reported by Hardacker et al., ${ }^{6}$ and this was consistent with the results reported by Goel and Shah. ${ }^{3}$ None of these patients had any evidence of CIS allograft collapse and/or resorption.

None of the 45 patients in our cohort had postoperative 
C-5 palsy. Although this result may be due to the small number of patients, the indirect formational decompression afforded by the interfacet spacers may have a protective effect against C-5 palsy. However, this is only a speculation at this point, and a larger series is needed to validate this hypothesis.

\section{Conclusions}

Cervical interfacet spacers do not significantly change preoperative cervical alignment. They can increase foraminal area and are positioned in an environment conducive to arthrodesis.

\section{References}

1. Abumi K, Shono Y, Ito M, Taneichi H, Kotani Y, Kaneda $\mathrm{K}$ : Complications of pedicle screw fixation in reconstructive surgery of the cervical spine. Spine (Phila Pa 1976) 25:962969, 2000

2. Fujimura Y, Nishi Y, Chiba K, Nakamura M, Hirabayashi $\mathrm{K}$ : Multiple regression analysis of the factors influencing the results of expansive open-door laminoplasty for cervical myelopathy due to ossification of the posterior longitudinal ligament. Arch Orthop Trauma Surg 117:471-474, 1998

3. Goel A, Shah A: Facetal distraction as treatment for singleand multilevel cervical spondylotic radiculopathy and myelopathy: a preliminary report. J Neurosurg Spine 14:689696, 2011

4. Gore DR, Sepic SB, Gardner GM: Roentgenographic findings of the cervical spine in asymptomatic people. Spine (Phila Pa 1976) 11:521-524, 1986

5. Han K, Lu C, Li J, Xiong GZ, Wang B, Lv GH, et al: Surgical treatment of cervical kyphosis. Eur Spine J 20:523-536, 2011

6. Hardacker JW, Shuford RF, Capicotto PN, Pryor PW: Radiographic standing cervical segmental alignment in adult volunteers without neck symptoms. Spine (Phila Pa 1976) 22:1472-1480, 1997

7. Heller JG, Silcox DH III, Sutterlin CE III: Complications of posterior cervical plating. Spine (Phila Pa 1976) 20:24422448, 1995

8. Hojo Y, Ito M, Abumi K, Kotani Y, Sudo H, Takahata M, et al: A late neurological complication following posterior correction surgery of severe cervical kyphosis. Eur Spine J 20:890-898, 2011

9. Ishihara A: [Roentgenographic studies on the normal pattern of the cervical curvature.] Nippon Seikeigeka Gakkai Zasshi 42:1033-1044, 1968 (Jpn)

10. Louis R: Spinal stability as defined by the three-column spine concept. Anat Clin 7:33-42, 1985
11. Nakashima H, Imagama S, Yukawa Y, Kanemura T, Kamiya M, Yanase M, et al: Multivariate analysis of C-5 palsy incidence after cervical posterior fusion with instrumentation. $\mathbf{J}$ Neurosurg Spine 17:103-110, 2012

12. Pal GP, Sherk HH: The vertical stability of the cervical spine. Spine (Phila Pa 1976) 13:447-449, 1988

13. Scheer JK, Tang JA, Smith JS, Acosta FL Jr, Protopsaltis TS, Blondel B, et al: Cervical spine alignment, sagittal deformity, and clinical implications. A review. J Neurosurg Spine 19:141-159, 2013

14. Shimizu K, Nakamura M, Nishikawa Y, Hijikata S, Chiba K, Toyama Y: Spinal kyphosis causes demyelination and neuronal loss in the spinal cord: a new model of kyphotic deformity using juvenile Japanese small game fowls. Spine (Phila Pa 1976) 30:2388-2392, 2005

15. Takeshita K, Murakami M, Kobayashi A, Nakamura C: Relationship between cervical curvature index (Ishihara) and cervical spine angle (C2-7). J Orthop Sci 6:223-226, 2001

16. Tan LA, Gerard CS, Anderson PA, Traynelis VC: Effect of machined interfacet allograft spacers on cervical foraminal height and area. J Neurosurg Spine 20:178-182, 2014 (Erratum in J Neurosurg Spine 20:772, 2014)

17. Tang JA, Scheer JK, Smith JS, Deviren V, Bess S, Hart RA, et al: The impact of standing regional cervical sagittal alignment on outcomes in posterior cervical fusion surgery. Neurosurgery 71:662-669, 2012

18. Tsuzuki N, Abe R, Saiki K, Iizuka T: Tension-band laminoplasty of the cervical spine. Int Orthop 20:275-284, 1996

\section{Author Contributions}

Conception and design: Traynelis. Acquisition of data: all authors. Analysis and interpretation of data: all authors. Drafting the article: Tan. Critically revising the article: all authors. Reviewed submitted version of manuscript: all authors. Approved the final version of the manuscript on behalf of all authors: Traynelis. Statistical analysis: Straus.

\section{Supplemental Information Videos}

Video 1, Media Player. http://mfile.akamai.com/21490/wmv/ digitalwbc.download.akamai.com/21492/wm.digitalsource-naregional/spine14-192_video_1.asx.

Video 1, Quicktime. http://mfile.akamai.com/21488/mov/ digitalwbc.download.akamai.com/21492/qt.digitalsource-global/ spine14-192_video_1.mov.

\section{Correspondence}

Vincent C. Traynelis, Department of Neurosurgery, Rush University Medical Center, 1725 W. Harrison St., Ste. 855, Chicago, IL 60612. email: vincent_traynelis@rush.edu. 